\title{
Comparative effects of different dietary levels of cellulose and fructooligosaccharides on fermenta- tive processes in the caecum of rats
}

\author{
A. Jurgoński ${ }^{1}$, J. Juśkiewicz and Z. Zduńczyk \\ Institute of Animal Reproduction and Food Research, \\ Polish Academy of Sciences, Department of Biological Analysis of Food \\ Tuwima 10, 10-747 Olsztyn, Poland
}

(Received 19 September 2007; revised version 15 November 2007; accepted 15 January 2008)

\begin{abstract}
Forty eight male Wistar rats were divided into 6 groups and fed over 4 weeks with diets containing $2.5,5$ or $10 \%$ addition of potentially inert carbohydrate cellulose (CEL) or easily fermentable fructooligosaccharides (FOS). In rats fed on CEL diets no substantial changes in the $\mathrm{pH}$, caecal mass, as well as protein, ammonia and short-chain fatty acids (SCFA) concentration in the caecal digesta were observed; almost all microbial enzymes activity also was not modified, except the activity of $\beta$-glucuronidase which decreased considerably upon higher doses of CEL ( 5 and 10\%). Lower FOS supplementation (2.5 and 5\%) led to desirable changes typical for dietary fructans (increased SCFA concentration and acidification of digesta), while the $10 \%$ addition of FOS had some unfavourable effects such as decreased SCFA concentration, especially butyrate, and excessive enlargement of the caecum (tissue and digesta). In conclusion, $10 \%$ addition of FOS seems to be an overdose, while CEL can be recognized as a good negative control in experiments with non-digestible saccharides, however, its influence on microflora activity should be considered during the interpretation of the obtained results.
\end{abstract}

KEY WORDS: fructooligosaccharides, cellulose, caecum, short-chain fatty acids, enzymes activity, rat

\section{INTRODUCTION}

In recent years, linear fructans have been one of the most extensively investigated group of non-digestible saccharides (Flickinger et al., 2003; Roberfroid, 2005).

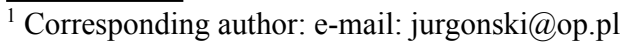


They consist of fructose molecules connected with each other by means of $\beta(2 \rightarrow 1)$ bonds forming different length chains, which are often bound with one molecule of glucose. The fructans, occurring in many plants, are not hydrolysed by pancreatic enzymes, but are broken down by specific bacteria in the hindgut. Therefore, they are categorized as substances with prebiotic properties and the part of dietary fibre (Roberfroid, 2005).

Fructooligosaccharides (FOS), also often called oligofructose, are a specific group of linear fructans whose degree of polymerization (DP) varies between 2 and 10. Administration of FOS leads to the enhancement of fermentative processes, as well as short-chain fatty acids (SCFA) production in the large intestine (Nyman, 2002). After absorption, these acids play important roles in an organism, namely propionate has a positive influence on lipid metabolism in liver, whereas butyrate is an energy substrate for colonocytes (Roberfroid, 2005). The levels of FOS which have been used as dietary additives in experiments with animals differ from 0.3 to $10 \%$ of a diet (Nyman, 2002; Flickinger et al., 2003). In the studies of caecal metabolism in rats the concentration of 5 to $10 \%$ of the diet have been used most frequently (Bielecka et al., 2002; Nyman, 2002; Juśkiewicz et al., 2005; Zduńczyk et al., 2005), however, the optimal amount of FOS has not been established thus far.

In order to estimate properties of non-digestible saccharides and their susceptibility to fermentation in the caecum, an inert carbohydrate is also needed to make a reference to experimental group. A substance which is often used in animal experiments as the negative control is cellulose (CEL). However, it has been reported that CEL may affect intestinal absorption by increasing digesta viscosity (Takahashi et al., 2005), and its varied quantities can be fermented by bacteria in the large intestine of rats (Hsu and Penner, 1989; Juśkiewicz et al., 2005). For these reasons the recognition of CEL as an inert dietary component to the caecum is not obvious.

The aim of this study was to compare the effects of different dietary levels of potentially inert carbohydrate cellulose and easily fermentable fructooligosaccharides on fermentative processes, including microbial enzymes activity and SCFA production in the caecum of rats.

\section{MATERIAL AND METHODS}

\section{Animals, diets and experimental conditions}

The experiment was conducted on forty eight, 5-week old male Wistar rats, weighing $98.5 \pm 7 \mathrm{~g}$, randomly divided into 6 groups of 8 animals each, and fed over 4 weeks with casein diets (Table 1). The main source of energy 
Table 1. Composition of the diets, $\%$

\begin{tabular}{lcccccc}
\hline \multirow{2}{*}{ Component } & \multicolumn{7}{c}{ Diet } \\
\cline { 2 - 7 } & CEL2.5 & CEL5 & CEL10 & FOS2.5 & FOS5 & FOS10 \\
\hline Casein & 14.8 & 14.8 & 14.8 & 14.8 & 14.8 & 14.8 \\
DL-methionine & 0.2 & 0.2 & 0.2 & 0.2 & 0.2 & 0.2 \\
Soyabean oil & 7.5 & 7.5 & 7.5 & 7.5 & 7.5 & 7.5 \\
Mineral mix $^{1}$ & 3.5 & 3.5 & 3.5 & 3.5 & 3.5 & 3.5 \\
Vitamin mix $^{1}$ & 2.0 & 2.0 & 2.0 & 2.0 & 2.0 & 2.0 \\
Cholesterol $_{\text {Cellulose }}$ & 0.5 & 0.5 & 0.5 & 0.5 & 0.5 & 0.5 \\
Fructooligosaccharides & 2.5 & 5.0 & 10.0 & - & - & - \\
Maize starch & - & - & - & 2.5 & 5.0 & 10.0 \\
\hline
\end{tabular}

${ }^{1}$ recommended for AIN-93G diet (Reeves, 1997)

in each groups was maize starch partly replaced with $2.5,5$ or $10 \%$ of cellulose in CEL2.5, CEL5 and CEL10 group, respectively, or fructooligosaccharides in FOS2.5, FOS5 and FOS10 group, respectively. The FOS preparation used in the experiment was Raftilose P95 produced by Orafti (Belgium), which was characterized by 3-7 degree of polymerization (DP), whereas the $\alpha$-cellulose preparation was obtained from Sigma-Aldrich (No. C8002). All animals were housed individually under the following standard conditions: temperature of $21-22^{\circ} \mathrm{C}$, relative humidity of $50-70 \%, 15$ air changes per $\mathrm{h}$ and $12 \mathrm{~h}$ lightning, they had also free access to water and diets.

\section{Procedures}

At the termination of the experiment, the rats were anaesthetized with $20 \%$ urethane in physiological salt according to the recommendation for euthanasia of experimental animals (Close et al., 1997). After laparotomy, caecum with contents was removed and weighed. The caecal $\mathrm{pH}$ was measured using a microelectrode and a $\mathrm{pH} / \mathrm{ION}$ meter (model 301, Hanna Instruments). Dry matter $\left(\right.$ at $105^{\circ} \mathrm{C}$ ), ammonia and SCFA were determined in fresh digesta, whereas protein content, as well as microbial enzymes activity were determined after storage at $-70^{\circ} \mathrm{C}$. The caecum wall was flushed clean with water, blotted on filter paper and weighed. Ammonia was extracted and trapped in a solution of boric acid, then determined by direct titration with sulphuric acid (Hofirek and Haas, 2001). The SCFA concentration was measured using gas chromatography under conditions described previously (Juśkiewicz and Zduńczyk, 2004). The SCFA caecal pool was calculated as the product of SCFA concentration $(\mu \mathrm{mol} / \mathrm{g})$ and relative digesta mass ( $\mathrm{g} / 100 \mathrm{~g}$ body weight). Protein content was determined in the supernatant of the digesta with the Lowry's method using bovine serum albumin as a standard (Lowry et al., 1951). The microbial enzymes activity ( $\alpha$ - 
and $\beta$-glucosidase, $\alpha$-and $\beta$-galactosidase, and $\beta$-glucuronidase) was measured by the rate of $\mathrm{p}$ - or o-nitrophenol release from their nitrophenyl-glucosides, and expressed as $\mu \mathrm{mol}$ of product formed per $\min (1 \mu \mathrm{mol} / \mathrm{min}=1$ Unit $)$ per $\mathrm{g}$ of caecal digesta or per $\mathrm{g}$ of protein (Juśkiewicz and Zduńczyk, 2004).

\section{Statistical analysis}

Statistical analysis was performed using two-way repeated measures analysis of variance with type of additive (A) and its level (L) as factors and their interactions $(\mathrm{A} \times \mathrm{L})$. Post hoc comparisons were made using the Duncan's multiple range test at a significance level of $\mathrm{P} \leq 0.05$. Standard error of the means (SEM) was calculated from the standard deviation from all rats divided by square root of rat number.

\section{RESULTS}

Diet intake, body weight gain and caecal parameters. Irrespectively of the level of the tested carbohydrates the diet intake differed significantly among rats fed with FOS and CEL addition ( $\mathrm{P} \leq 0.05)$, while body weight $(\mathrm{BW})$ gain did not differ between all experimental groups. The contents of CEL in experimental diets did not substantially modify $\mathrm{pH}$, ammonia nor protein concentration $(\mathrm{mg} / \mathrm{g})$ in the caecal digesta, as well as relative tissue and digesta mass (Table 2). However, dry matter did not change in the CEL groups only when calculated per $100 \mathrm{~g}$ of BW. The FOS administration led to a significant, directly proportional to the dose, decrease of caecal $\mathrm{pH}$ as well as an increase of relative tissue mass and protein concentration. Relative digesta mass and dry matter pool (g/100 g BW), as well as ammonia and protein pool (mg/100 g BW) were significantly higher in FOS10 group, when compared to the other FOS groups. On general, FOS supplementation of the diet in relation to CEL essentially increased tissue and digesta mass, protein concentration, ammonia and protein pool, as well as decreased caecal $\mathrm{pH}$ and dry matter of digesta (\%). Moreover, the two-way analysis of variance of almost all tested caecal parameters revealed strong interactions between the type and level of carbohydrates in the $\operatorname{diet}(\mathrm{P} \leq 0.001)$.

Microbial enzymes activity. Microbial enzymes activity in caecal digesta of rats is shown in Table 3. The activity of $\alpha$ - and $\beta$-glucosidase, as well as $\alpha$ - and $\beta$-galactosidase did not substantially differ among all CEL groups, but $\beta$-glucuronidase activity was statistically lower in CEL5 and CEL10 than in the CEL2.5 group. The FOS10 administration led to a decrease of all enzymes activity in the caecal digesta when compared to FOS2.5 and FOS5 groups. Moreover, the activities of particular enzymes (Units/g protein) were more than twofold lower in the FOS10 when compared to the other FOS groups. Statistical 


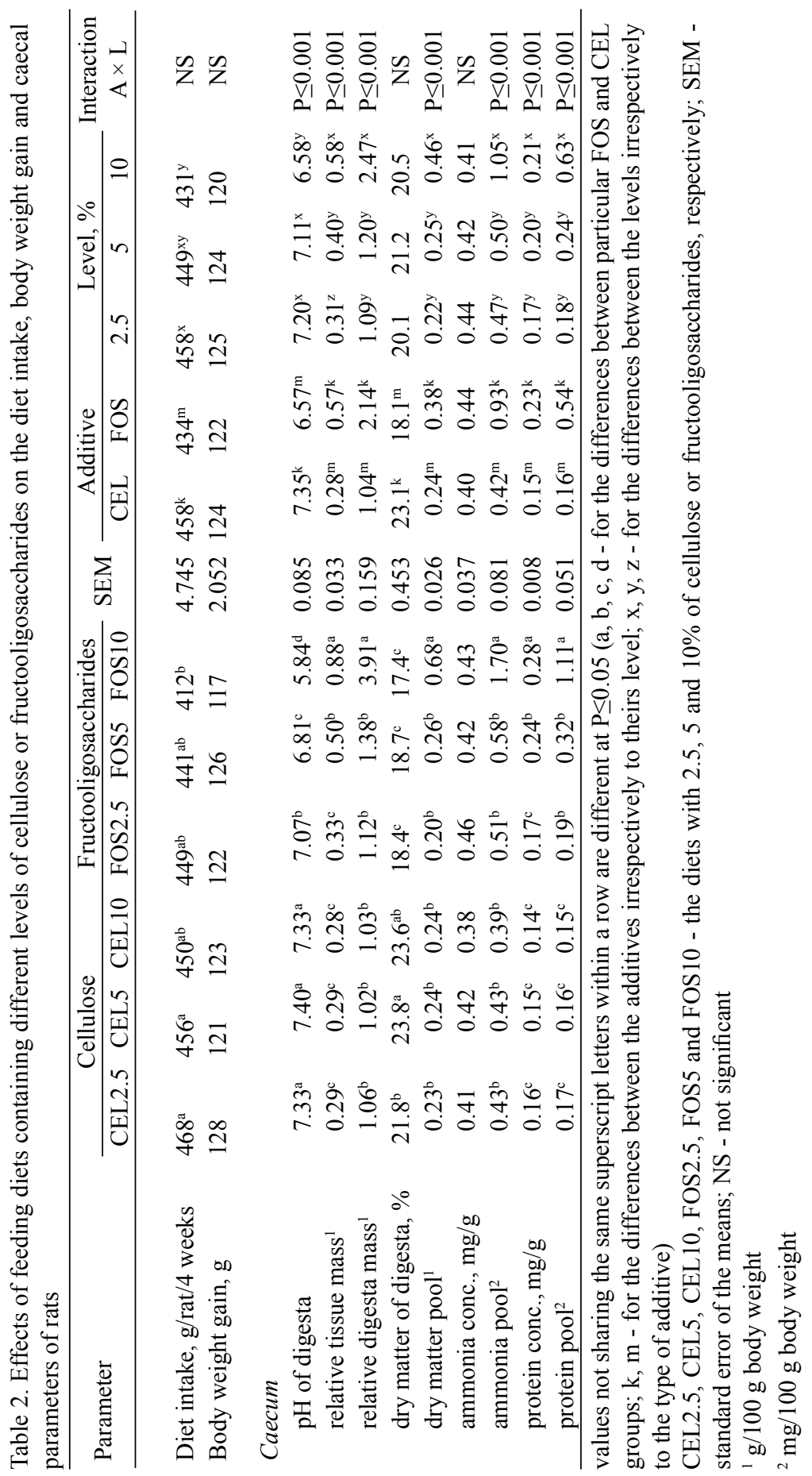




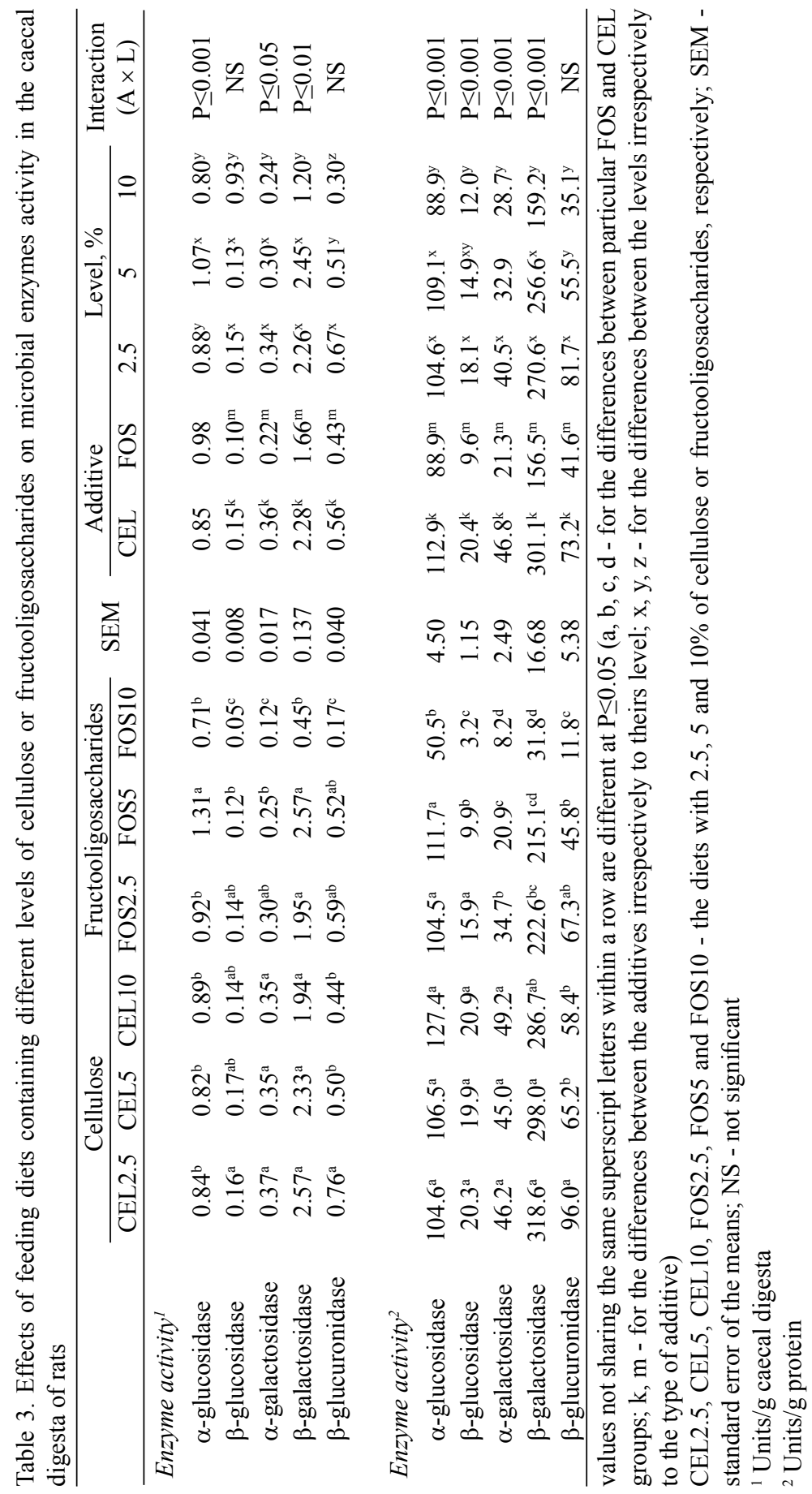




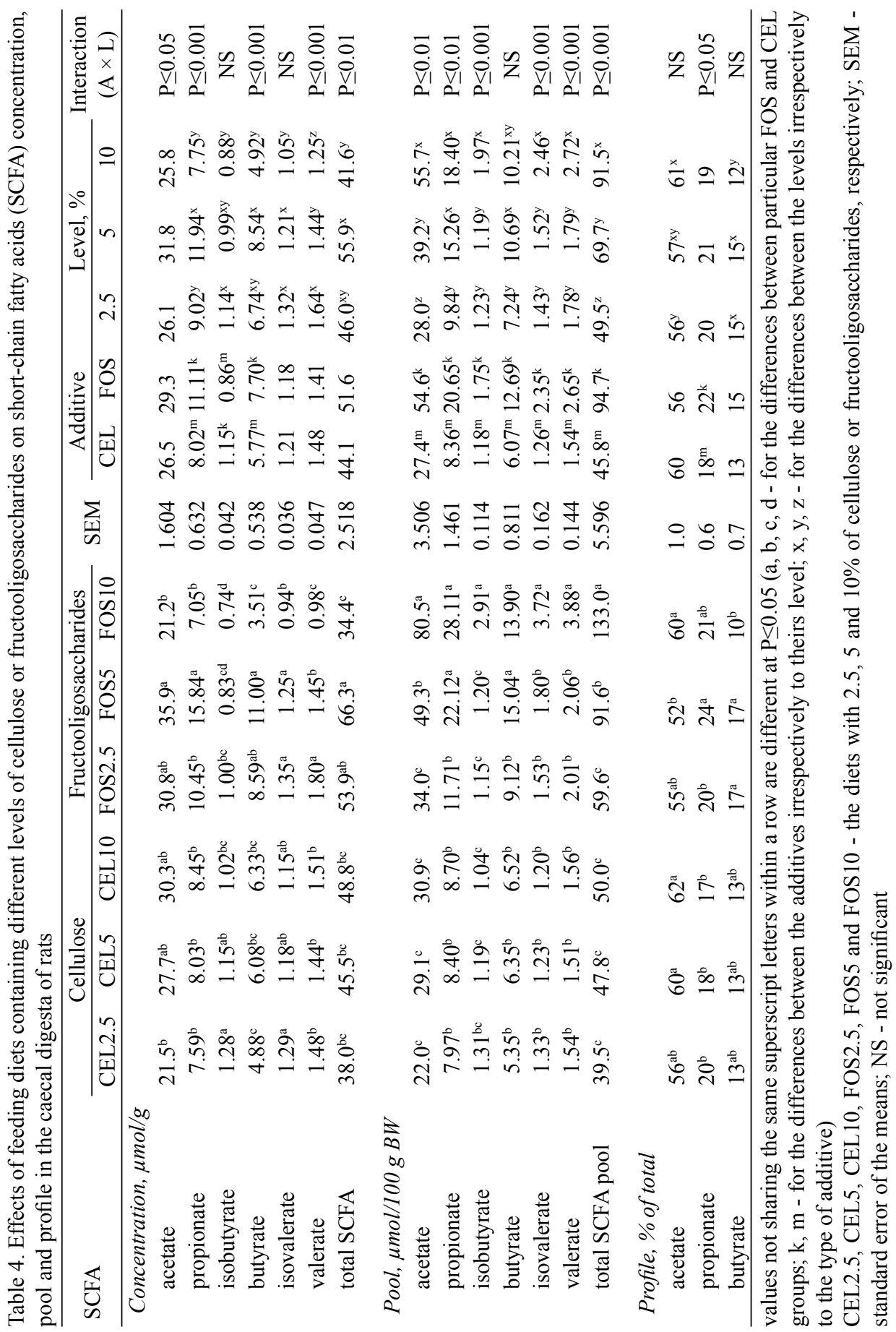


analysis also showed significant interactions between the type and level of additives in the case of all examined enzymes, except $\beta$-glucuronidase.

Short-chain fatty acid (SCFA) production. The concentration of total and individual SCFA did not substantially differ in CEL groups, except isobutyrate, the concentration of which differed between the CEL10 and CEL2.5 group (Table 4). The highest concentrations of total and major (acetic, propionic and butyric) SCFA were observed in the FOS5 group, whereas the FOS2.5 group was characterized by the highest concentration of isobutyrate, isovalerate and valerate. The lowest concentration of all SCFA was noted in the FOS10 group. Irrespectively to the percentage content, FOS supplementation of the diet in relation to CEL essentially increased propionate and butyrate, as well as decreased isobutyrate concentration in the caecal digesta. Moreover, the two-way analysis of variance of acetate, propionate, butyrate and valerate concentrations revealed significant interactions between the factors.

Total and particular SCFA pool size were not statistically affected by CEL addition, while the total SCFA pool in FOS groups strongly depended on the percentage content of FOS (Table 4). The highest total and individual SCFA pool, except butyrate, were in caecal digesta of animals fed a diet with $10 \%$ of FOS, while the lowest ones were in the FOS2.5 group. The butyrate pool was slightly decreased in the FOS10 group when compared with the FOS5. Moreover, the isobutyrate and isovalerate pool were more than twofold higher in FOS10 group than in the other FOS groups. Generally, FOS addition led to a significant increase of total and particular SCFA pool size, when compared with CEL. In addition, strong interactions among the analysed factors were also revealed when considering total and individual SCFA pool, except butyrate.

The different content of CEL also did not substantially change the profile of the major acids (Table 4 ) while the $10 \%$ addition of FOS significantly increased acetate and decreased butyrate proportion, when compared to the FOS5 and FOS2.5 groups, the highest propionate proportion was in the FOS5 group. Irrespectively to the level of the tested carbohydrates, supplementation of FOS substantially increased propionate proportion, and had no influence on acetate and butyrate.

\section{DISCUSSION}

We observed reduced diet intake after FOS supplementation in relation to CEL. This result confirmed the latest single-blinded, placebo-controlled study where authors demonstrated that FOS promoted satiety and reduced energy intake in healthy humans (Cani et al., 2006). However, the body weight gain did not change in our study, probably a longer period of feeding could reveal also more substantial fluctuation of the body weight of the animals. 
A number of authors indicate that the acidification of digesta promotes positive microflora proliferation and decreases the growth of pathogenic bacteria species (Topping and Clifton, 2001). Present study showed that even a small inclusion of FOS to the diet $(2.5 \%)$ decreased $\mathrm{pH}$ of digesta, and after the 5 and $10 \%$ addition, the caecal environment became more and more acidic. This effect was not observed in CEL groups where $\mathrm{pH}$ and the other tested caecal parameters did not change statistically. Also our earlier experiment demonstrated no differences between rats fed a diet with $8 \%$ of CEL or sucrose when considering caecal parameters, i.e. $\mathrm{pH}$ of digesta, tissue and digesta mass and ammonia concentration (Zduńczyk et al., 2004). Kim et al. (1998) suggest that 10\% addition of CEL to the rat diet may decrease urease activity and ammonia production in the caecum, however it was not confirmed. It is well known that ammonia liberated from proteins, as a result of putrefactive processes, can exert toxic effects on colonocytes and is implicated in carcinogenesis (Visek, 1978; Rasmussen et al., 1988). In our study, protein concentration was similar in groups fed different CEL levels and depended strongly on the dose of FOS, however, ammonia concentration did not change in either FOS and CEL groups. It indicates a more intensive synthesis of proteins by local microflora under the influence of higher levels of FOS. On the contrary, after $10 \%$ addition of FOS a few fold increase of ammonia and protein pool were observed, yet, these results were rather a simple consequence of an increased bulk of digesta. In fact, a higher amount of FOS $(10 \%)$ led to some consequences which can be considered as causing discomfort to the host, such as almost threefold enlargement of the caecum (tissue and digesta), when compared to all CEL and FOS2.5 groups. Interestingly, the mass of digesta did not differ among the FOS2.5 and FOS5 groups, therefore the substantial enlargement of the caecal tissue in the FOS5 group might be in part a positive consequence of increased butyrate production, which is known as the main energy substrate for colonocytes (Roberfroid, 2005). On the contrary, in the FOS10 group the enlargement was mainly a consequence of to intensive bulking effect.

Bielecka et al. (2002) have showed that the $10 \%$ inclusion of FOS significantly decreased $\alpha$-galactosidase and $\beta$-glucosidase activity, while the activity of $\alpha$ glucosidase, $\beta$-galactosidase and $\beta$-glucuronidase did not change statistically when compared to the CEL-enriched diet. In our experiment, the $10 \%$ addition of FOS distinctly decreased the activity of all microbial enzymes in the caecal digesta when compared with other CEL and FOS groups. It is common knowledge that FOS are prebiotics which selectively stimulate the growth of Bifidobacteria and, to a lesser extent, some other bacteria in the hind gut, due to a high activity of the intracellular inulinase in these microorganisms (Kleessen et al., 2001; Roberfroid, 2005). Therefore, we speculate that these bacteria can inhibit expansion of another microflora in the caecum, with significantly higher activity of the measured enzymes. 
The mechanism of the inhibition is probably a result of lower inulinase activity or its lack in inhibiting microorganisms, and after specific microflora multiplication some other factors could be joined, e.g., acidification of the environment and production of bacteriocins. Roberton et al. (1982) suggest that the most important factor in modulation of $\beta$-glucuronidase activity in the rat's large bowel is a bile flow. These findings seems to be in agreement with our results of decreased $\beta$-glucuronidase activity after addition of higher levels of CEL and FOS (5 and 10\%), since - as it is well known - both these carbohydrates stimulate peristalsis. However significantly lower activity of the enzyme obtained after $10 \%$ supplementation of FOS (vs CEL10 and other groups) indicates the mechanism with microorganisms inhibition, as well. Furthermore, also Lindop et al. (1985) demonstrated significantly lower $\beta$-glucuronidase activity after 16 weeks of feeding rats either with a diet containing $15 \%$ addition of CEL or with a fibre-free diet. For this reason the authors pointed at CEL as one of the factors which can diminish the quantity of intestinal neoplasia promoters. Thus, the collected data indicate that CEL is not thorough inert to the caecum, while FOS also may be considered as an anticancerogenic factor.

Hara et al. (1996) observed no significant differences in total SCFA concentration between rats obtaining a diet with or without $10 \%$ of CEL. As indicated earlier, the SCFA pool size provides more precise information than SCFA concentration about fermentation intensity of non-digestible saccharides (Zduńczyk et al., 2005). In our experiment, the total and individual SCFA pool, as well as total SCFA concentration did not substantially change in the groups with CEL addition, however, an upward tendency could be observed, except for isobutyrate and isovalerate where a reverse trend occurred. These results indicate that CEL may be, in small quantities, a substrate of SCFA production by intestinal bacteria. Explanation of this rising trend might be the report of Hsu and Penner (1989), where 5\% inclusion of microcrystalline CEL to the diet led to its $8.8 \%$ digestibility, determined in rat faeces. Present study shows that the highest production of both total SCFA and butyrate was observed in the rats fed diets with $5 \%$ addition of FOS. Nilsson and Nyman (2005) pointed at FOS with $\mathrm{DP}=3-8$, as carbohydrates which can yield the highest SCFA production, especially butyrate in the rat's caecum. However, $10 \%$ addition of FOS in our experiment significantly depressed butyrate and total SCFA concentrations. These results seem to be disturbing in the context of healthpromoting properties of butyrate, which is suggested to protect against colonic disease, e.g., ulcerative colitis, cancer, intestinal upsets and diarrhoea (Kleessen et al., 2001; Flickinger et al., 2003), and overdosing of FOS-rich nutraceutics by humans or growth stimulator substitutes with high amounts of FOS in animal feeds, could brought effects contrary to the expected ones. 


\section{CONCLUSIONS}

The results presented above indicate that CEL affect, to some extent, the caecal environment by beneficial decreasing of $\beta$-glucuronidase activity. In spite of this, our results proved that CEL can be recognized as a good negative control in experiments where properties of non-digestible saccharides are tested. However, its influence on microflora activity should be considered during the interpretation of the obtained results.

Our study also showed that addition of FOS up to $5 \%$ of the diet, led to positive changes in the caecum which are typical of fructans, e.g., acidification of digesta and an increase of SCFA concentration. Ten percent supplementation of FOS seems to be an overdose leading to such undesirable effects as decreased SCFA concentration, especially butyrate, and excessive enlargement of the caecal tissue and digesta, however without any unfavourably increase of ammonia concentration and $\beta$-glucuronidase activity.

\section{REFERENCES}

Bielecka M., Biedrzycka E., Majkowska A., Juśkiewicz J., Wróblewska M., 2002. Effect of nondigestible oligosaccharides on gut microecosystem in rats. Food Res. Int. 35, 139-144

Cani P.D., Joly E., Horsmans Y., Delzenne N.M., 2006. Oligofructose promotes satiety in healthy human: a pilot study. Eur. J. Clin. Nutr. 60, 567-572

Close B., Banister K., Baumans V., Bernoth E.-M., Bromage N., Bunyan J., Erhardt W., Flecknell P., Gregory N., Hackbarth H., Morton D., Warwick C., 1997. Recommendations for euthanasia of experimental animals: Part 2. Lab. Anim. 31, 1-32

Flickinger E.A., Van Loo J., Fahey G.C., 2003. Nutritional responses to the presence of inulin and oligofructose in the diets of domesticated animals: a review. Crit. Rev. Food Sci. Nutr. 43, 19-60

Hara H., Suzuki K., Kobayashi S., Kasai T., 1996. Fermentable property of dietary fiber may not determine cecal and colonic mucosal growth in fiber-fed rats. J. Nutr. Biochem. 7, 549-554

Hofirek B., Haas D., 2001. Comparative studies of ruminal fluid collected by oral tube or by puncture of the caudorental ruminal sac. Acta Vet. Brno 70, 27-33

Hsu J.C., Penner M.H., 1989. Influence of cellulose structure on its digestibility in the rat. J. Nutr. $119,872-878$

Juśkiewicz J., Zduńczyk Z., 2004. Effects of cellulose, carboxymethylcellulose and inulin fed to rats as single supplements or in combinations on their caecal parameters. Comp. Biochem. Physiol. Pt A 139, 513-519

Juśkiewicz J., Zduńczyk Z., Wróblewska M., 2005. The effect of the administration to rats of cellulose and fructans with different degree of polymerization on caecal fermentation and biochemical indicators in the serum. Czech J. Anim. Sci. 50, 273-280

Kim K.-I., Lee W.-S., Benevenga N.J., 1998. Feeding diets containing high levels of milk products or cellulose decrease urease activity and ammonia production in rat intestine. J. Nutr. 128, 11861191

Kleessen B., Hartmann L., Blaut M., 2001. Oligofructose and long-chain inulin influence the gut microbial ecology of rats associated with a human faecal flora. Brit. J. Nutr. 86, 291-230 
Lindop R., Tasman-Jones C., Thomsen L.L., Lee S.P., 1985. Cellulose and pectin alter intestinal beta-glucuronidase (EC 3.2.1.31) in the rat. Brit. J. Nutr. 54, 21-26

Lowry O.H., Rosebrough N.J., Farr A.L., Randall R.J., 1951. Protein measurement with the folin phenol reagent. J. Biol. Chem. 193, 265-275

Nilsson U., Nyman M., 2005. Short-chain fatty acid formation in the hindgut of rats fed oligosaccharides varying in monomeric composition, degree of polymerisation and solubility. Brit. J. Nutr. 94, 705-713

Nyman M., 2002. Fermentation and bulking capacity of indigestible carbohydrates: the case of inulin and oligofructose. Brit. J. Nutr. 87, 163-168

Rasmussen H.S., Holtug K., Mortensen P.B., 1988. Degradation of amino acids to short-chain fatty acids in humans. An in vitro study. Scand. J. Gastroenterol. 23, 178-182

Reeves P.G., 1997. Components of the AIN-93 diets as improvements in the AIN-76A diet. J. Nutr. $127,838-841$

Roberfroid M.B., 2005. Introducing inulin-type fructans. Brit. J. Nutr. 1, 13-25

Roberton A.M., Lee S.P., Lindop R., Stanley R.A., Thomsen L., Tasman-Jones C., 1982. Biliary control of beta-glucuronidase activity in the luminal contents of the rat ileum, cecum, and rectum. Cancer Res. 42, 5165-5166

Takahashi T., Karita S., Ogawa N., Goto M., 2005. Crystalline cellulose reduces plasma glucose concentrations and stimulates water absorption by increasing the digesta viscosity in rats. J. Nutr. 135, 2405-2410

Topping D.L., Clifton P.M., 2001. Short-chain fatty acids and human colonic function: roles of resistant starch and nonstarch polysaccharides. Physiol. Rev. 81, 1031-1064

Visek W.J., 1978. Diet and cell growth modulation by ammonia. Amer. J. Clin. Nutr. 31, 216-220

Zduńczyk Z., Juśkiewicz J., Wróblewska M., Król B., 2004. Physiological effects of lactulose and inulin in the caecum of rats. Arch. Anim. Nutr. 58, 89-98

Zduńczyk Z., Król B., Juśkiewicz J., Wróblewska M., 2005. Biological properties of fructooligosaccharides with different contents of kestose and nystose in rats. Arch. Anim. Nutr. $59,247-256$ 